\title{
Marine tetracyclic isoprenoids: structure and biosynthesis
}

\author{
G.B. Elyakov, V.A. Stonik, E.V. Levina \\ Pacific Institute of Bioorganic Chemistry, Far Eastern Branch \\ of the USSR Academy of Sciences, Vladivostok 690022 , U.S.S.R.
}

\begin{abstract}
The present short review deals with new sulfated and glycosylated derivatives of marine tetracyclic isoprenoids isolated in our laboratory from echinoderms and sponges. Structures of about 30 of such products, some spectroscopic details, data on their biological activity and hypothetic pathways of biosyntesis have been discussed.
\end{abstract}

\section{INTRODUCTION}

Different marine organisms that have been studied in the last two decades have yielded a variety of new natural products. Following structural investigations knowledge about biosynthetic processes in marine plants and animals is rapidly increasing ( Ref. 1-3). It is obvious that there are some peculiarities in the biochemistry of marine secondary metabolites, differing them from terrestrial ones. Wide distribution of water soluble natural products proved to be in many species, especially in marine invertebrates. For example, sulfatation and glycosylation reach such a high level in marine invertebrates as they never presumably do in terrestrial organisms.

This paper is devoted to marine tetracyclic isoprenoids, isolated from echinoderms and sponges. We would like to touch upon some problems concerning the origin of marine biochemical deviations from "typical behavior" using this group of compounds as an example.

\section{SULFATED DERIVATIVES}

Wide occurrence of sulfated tetracyclic isoprenoids was demonstrated by studies on natural products from sponges and echinoderms. In terrestrial organisms sulfate esters of mucopolysacharides, steroids and phenols are also of general occurrence but marine organisms have higher content of sulfated natural products. It was shown that a correlation exists between the concentration of those and the salinity of habitat (Ref. 4). Moreover, low molecular weight compounds from marine organisms often contain two or even three sulfate groups.

Corresponding steroids $(1,2)$ have been isolated from the ophiuroid ophiura sarsi together with monosulfates $(3,4)$. Structures were solved by a combination of chemical and spectroscopic studies. The downfield shift was observed in the proton NMR spectrum for $\mathrm{CH}_{3}-19$ signal of 3 compared with 4 (Ref.5). Related derivatives (5-8) with sulfated $2 \beta, 3 a-d i 0 l$ fragment (Ref.6-8) together with halistanol sulfate (9) of Fusetani et.al (Ref.9) were found from sponges. steroids (5-9) form a new series of physiologically active compounds. This series is composed of the most sulfated low molecular weight natural products having up to three sulfated hydroxyl and side chains with several extra methyl groups.

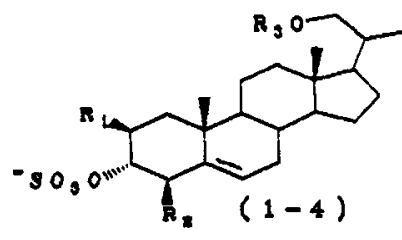

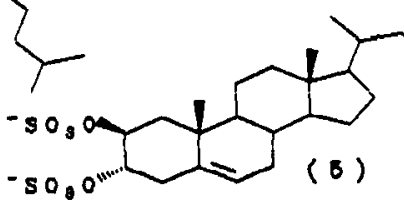<smiles>CC(C)(C)C(C)(C)C</smiles>

$R_{1}-H_{1} R_{2}-O H_{1} R_{A}-S O O_{Q}-(1)$

$R_{1}-O H_{1}, R_{A}-H_{1} R_{0}-50,-(a)$

$R_{1}-R_{B}-H ; R_{2}=O H(s)$

$R_{1}-R_{B}-H ; R_{*}-O A \circ(4)$

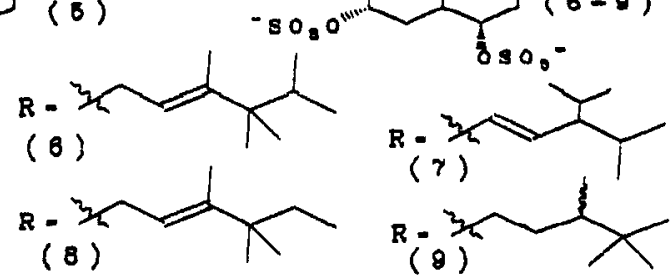


Taking into account the isolation of sulfate (5) as probable biogenetic intermediate we suppose that the formation of trisulfated steroids from sponges includes two successive epoxidations followed by opening of epoxylcycles and sulfatation :

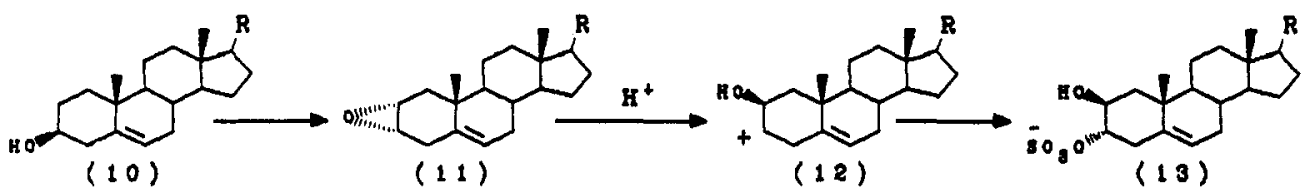

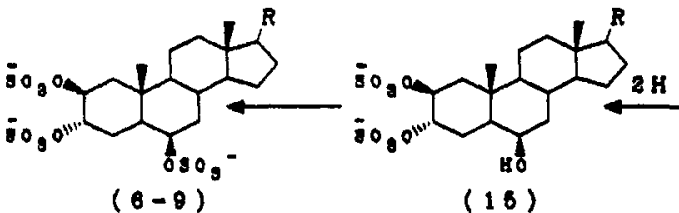

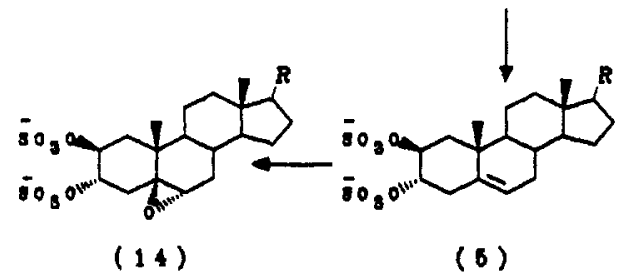

Biosynthesis of 6 and 8 is obviously the result of several s-adenosylmethionine (SAM) biomethylations followed by elimination of a proton from carbonium ions. Codisterol or epicodisterol (side chain 17) could be biosynthetic precursors as it was suggested by Djerassi et.al (Ref. 10 ) for some unusual sponge sterols.

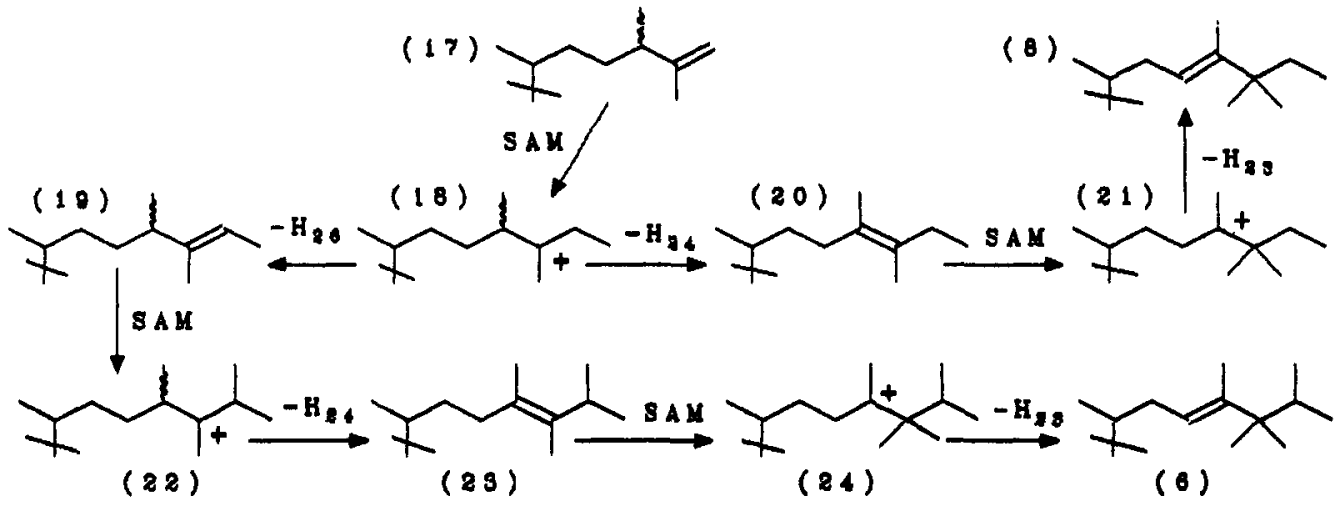

The presence of various sulfated tetracyclic isoprenoids in marine organisms shows these animals and plants to contain a set of related enzymes transferring sulfate from adenos ine-3'-phosphate-5'-phosphosulfate to isoprenoids. Sulfuric acid esters (25-28) have been isolated by us and Komori et.al. (Ref. 11-13) from the Far Eastern starfish Patiria (= Asterina) pectinifera. It seems that different enzymes provide sulfatation at $c-3$ of 25 and 26 , at $c-7$ of 27 or into an arabinosy 1 residue of 28. Sufficient data have been accumulated to support the hypothesis that several enzymes carry out the sulfatation in the process of glycoside biosynthesis in holoturians. Sulfated group is always located at C-4 of xylose in glycosides from the Holothuriidae family as it takes place in holothurin A1 (29) (Ref.14). So-called psolusoside A (30) from the Psolidae family is twice sulfated : at C-6 of glucose and $3-0$ methylglucose (Ref.15). Finally, glycoside (31) from Cladolabes sp. contains sulfate group both at C6 of glucose and C-4 of xylose. Although all above mentioned glycosides possess sulfate groups in different positions, there is no difference in other details of their carbohydrate chains (Ref.16).

Thus sulfatation leads in marine organisms to a wide range of water-soluble metabolites including derivatives of tetracyclic isoprenoids from echinoderms and sponges.

\section{GLYCOSYLATED DERIVATIVES}

Other wide spread method of water-soluble natural products' biosynthesis is glycosylation. steroid and triterpenoid glycosides and especially oligoglycosides are practicaliy unknown as metabolites of terrestrial animals. 


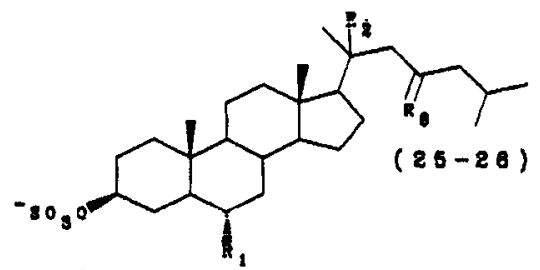

$\Delta{ }^{0} ; R_{1}-R_{2}-H_{i} R_{3}-H_{9}(25)$ $\Delta^{O(11) ; R_{1}-C \text { arbohydrate }}$ $R_{\mathrm{A}}=\mathrm{OH} ; R_{\mathrm{B}}-\mathrm{O}(2 \theta)$

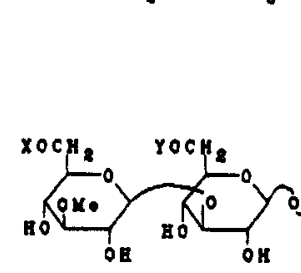

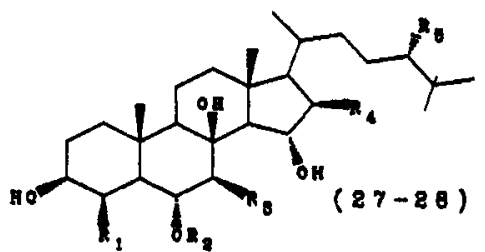
$R_{1}-R_{G}-R_{6}-O H_{i} R_{g}-5 O_{3}^{-} ;$ $\mathrm{A}_{\mathrm{B}}-\mathrm{H} ;(\mathrm{a})$ $R_{1}-R_{8}-R_{3}=R_{4}=H_{i}$

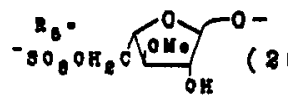

However, they have already been found from marine animals in echinoderms, sponges, alcyonarians and fishes. There is a variety of directions for

glycosylation in marine animals compared with terrestrial organisms. Carbohydrate chains have liner structure in families Holothuritidae and, probably, Gephirothuriidae from the Aspidochirota order holothurians. Recently we established the structure (32) for a new glycoside from Pseudostichopus trachus belonging to the second family. Giycosides from more ancient order Dendrochirota often contain the branched carbohydrate moieties as exemplified in (33) from Psolus fabricii (Ref.16-17). Glycosides having no $18 \rightarrow 20$ lactone were found so far only in this order. Comparison of hemolytic action demonstrated higher level of that for holostane derivatives ( containing 18 20 lactone).

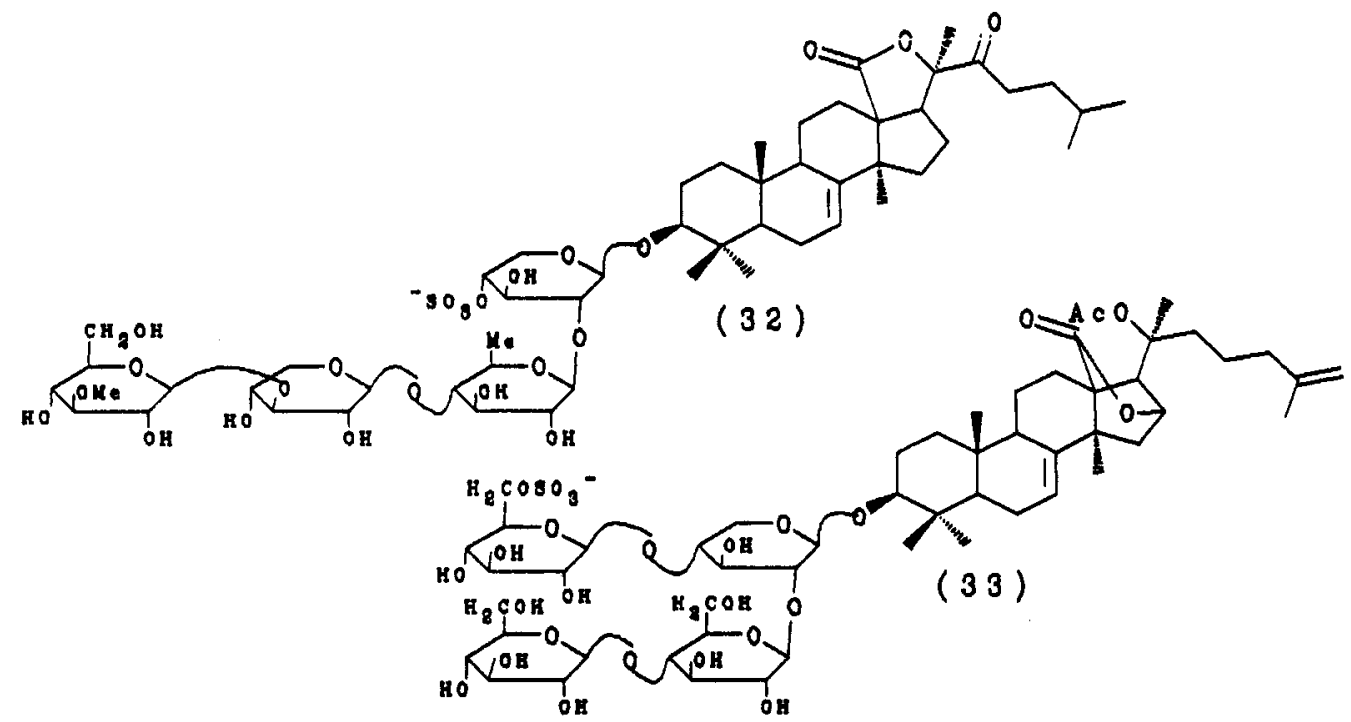

We have isolated from starfishes a series of new glycosylated steroid polyols with monosaccharide or disaccharide fragments in side chains. Structures of culcitosides ( $34 \mathrm{a}, \mathrm{b}$ ) from Culcita novaeguinea (Ref.18), asterosaponin P2 (35) from Patiria pectinifera ( Ref.19), crossasterosides ( 36 a,b, 37 ) from Crossaster paposus (Ref.20) demonstrated the remarkable variety of glycosylations in starfishes. Carbohydrate fragments in these compounds are located at $\mathrm{C}-24, \mathrm{C}-26, \mathrm{C}-28, \mathrm{C}-29$ of aglycones.

The majority of water-soluble isoprenoid metabolites from echinoderms and sponges are amphiphylic compounds. The selection of such metabolites is connected with the necessity to provide the affinity to hydrophobic cellular membranes, where receptors are localized, and good transport properties in water. 


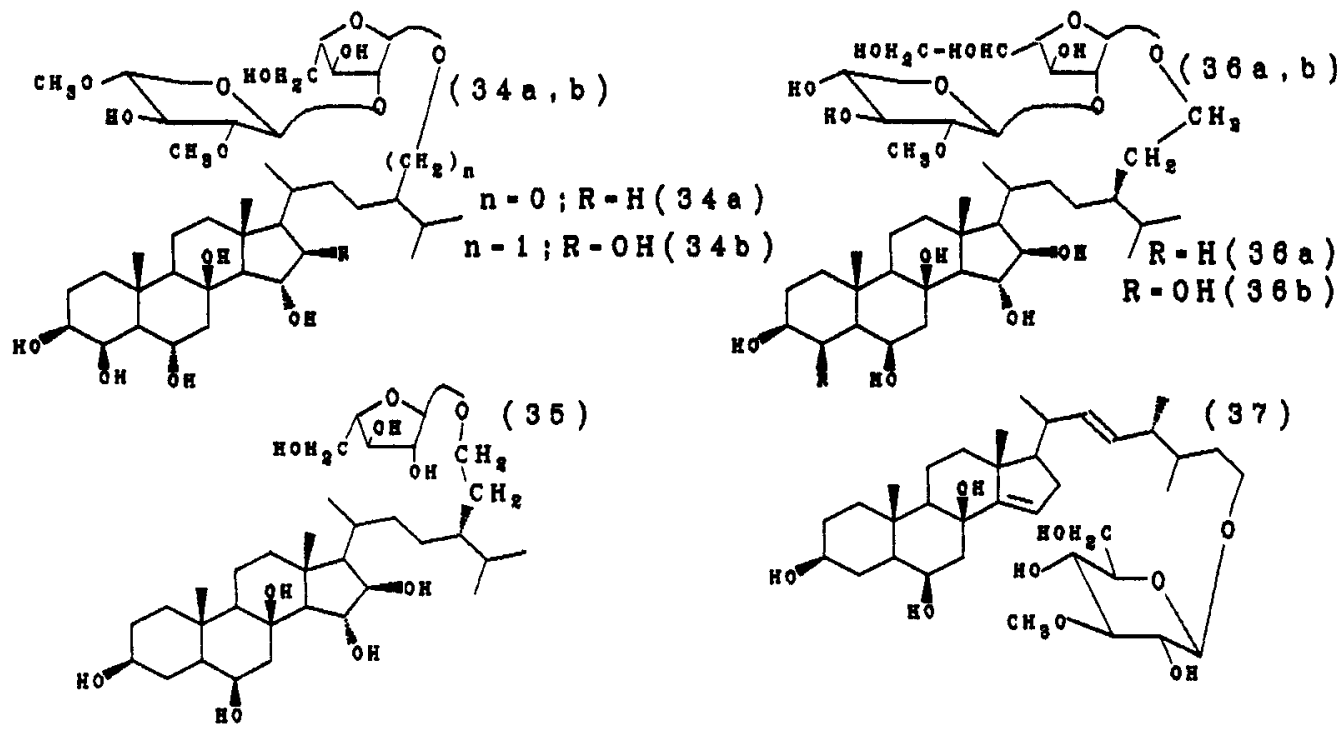

\section{CONCLUSION}

The reason of wide distribution of sulfated, glycosylated, and polyhydroxylated compounds in marine organisms is that there was evolutionary influence of surrounding medium upon biochemical reactions. This influence could firstiy express itself by inclusion of sea water components in biosynthetic processes. Adaptive selection of secondary metabolites with the purpose of chemical communications and for other aims could also be the case of rise of such peculiarities as massive sulfatation and glycosylation.

\section{REFERENCES}

1. P.J. Scheuer (ed.), Marine natural products chemical and biological perspectives, AC.Press, N.Y., vol. 1-5 (1978-1983).

2. H.S. Krebs, Fortshr. Chem. Org. Naturst., 35, 152-163 (1986).

3. P.J. Scheuer (ed.), Marine Bioorganic Chemistry, Springer-verlag, Berlin, vol.1,2, (1987-1988).

4. C. Christophersen, $U$. Anthoni, sulfur Reports, 4, 365-442 (1986).

5. E.V. Levina, A.I. Kalinovsky, V.A. Stonik et al., Khim. Prir. Soedin., 24, 375-379 (1988).

6. T.N. Makariova, L.K. Shubina, A.I. Kalinovsky et.a1., Steroids, 42, 267$292(1983)$.

7. T.N. Makarieva, L.K. Shubina, V.A. Stonik, Khim. Prir. Soedin., 23, 111$115(1988)$.

8. T.N. Makarieva, L.K. Shubina, A.I. Kalinovsky et.al., Khim. Prir. Soedin., $24,371-375(1988)$.

9. N. Fusetani, S. Matsunaga, S. Konosu, Tetr. Lett., 21, 1985-1988 (1981).

10. C. Djerassi, Pure App 1. Chem., 53, 873-890 (1981).

11. R. Higuchi. Y. Noguchi, T. Komori, T. Sasaki, LieB. Ann. Chem., 1988, 11851189 .

12. A.A. Kicha, A.I. Kalinovsky, E.V. Levina et.a1.,Tetr. Lett., 24, 3893-3897 $(1983)$

13. A.A. Kicha, A.I. Kalinovsky, E.V. Levina, Khim. Prir. Soedin., 20, 738$741(1984)$.

14. G.K. Oleynikova, T.A. Kuznetsova, N.S. Ivanova et.al., Khim. Prir. Soedin., $20,215-219(1984)$.

15. V.I. Kalinin, A.I. Kalinovsky, V.A. Stonik, Khim. Prir. Soedin., 21, 212$217(1985)$.

16. V.A. Stonik, G.B. Elyakov in Marine Bioorg. Chem., P.J. Sheuer (ed.), Springer-Verlag, Berlin, vol. 2, 43-86 (1988).

17. V.I.Kalinin, A.I. Kalinovsky, V.A. Stonik et.al., Khim. Prir. Soedin., 25, $36 \uparrow-362(1989)$

18. A.A.Kicha, A.I. Kalinovsky, P.V. Andriyaschenko et.al., Khim. Prir. Soedin., 22, 592-596 (1986).

19. A.A.Kicha, A.I. Kalinovsky, E.V.Levina et.al., Khim. Prir. Soedin., 21, 356-361 (1986).

20. A.A.Kicha, A.I. Kalinovsky, V.A.Stonik in IX Soviet-Indian Symp. Chem. Nat. Prod., Riga, 18-19 (1989) 